\title{
Degradación ruminal en bovinos de la materia seca de Sorghastrum setosum a diferentes edades en época otoñal
}

\author{
Slanac, A.L. ${ }^{1}$ Kucseva, C.D. ${ }^{2}$; Balbuena, O. ${ }^{3}$, Rochinotti, D. ${ }^{4}$
}

${ }^{1}$ Cátedra de Fisiología, ${ }^{3}$ Cátedra de Nutrición y Alimentación Animal, Facultad de Ciencias Veterinarias, Universidad Nacional del Nordeste, Sargento Cabral 2139, Corrientes (3400), Argentina, Tel 03783425753.

${ }^{2}$ INTA, Colonia Benítez (Argentina), ${ }^{4}$ INTA (Mercedes, Argentina). E-mail: alslanac@vet.unne.edu.ar.

\begin{abstract}
Resumen
Slanac, A.L.; Kucseva, C.D.; Balbuena, O.; Rochinotti, D.: Degradación ruminal en bovinos de la materia seca de Sorghastrum setosum a diferentes edades en época otoñal. Rev. vet. 22: 2, 105-108, 2011. Con el objetivo de evaluar la degradación ruminal de la materia seca (MS) de Sorghastrum setosum ("paja amarilla") en rumen de bovinos en época otoñal, se recolectaron muestras de dicha pastura a los 15,30 y 45 días de rebrote. Para valorar la degradación de la MS se utilizó la técnica de suspensión in situ de bolsas de dacrón en rumen de novillos cruza cebú de $550 \mathrm{~kg}$ de peso vivo provistos de fístula ruminal, las que fueron incubadas durante $0,3,6,12,24,48,72$ y $120 \mathrm{~h}$. Una vez retiradas del rumen, las bolsas fueron secadas a $60^{\circ} \mathrm{C}$ durante $72 \mathrm{~h}$ y pesadas. La pérdida de peso se consideró como el valor de desaparición de MS. Los datos fueron analizados mediante el procedimiento GLM del paquete estadístico SAS. Los resultados obtenidos de la degradabilidad ruminal de la MS para el rebrote de 15, 30 y 45 días, muestran que no se detectaron diferencias significativas $(\mathrm{p}>0,05)$, para la fracción soluble, fracción de degradación lenta, tasa de degradación lenta, fracción indigestible y degradación ruminal efectiva. Para los cálculos se asumieron tasas de pasaje normales para este material, del 2 y $4 \%$ / hora. El análisis de la varianza solo detectó una tendencia a ser diferente entre edades de rebrote para el tiempo de inicio de la degradación $(p=0,09)$. Se concluye que en la estación otoñal, la edad de rebrote no influye sobre la degradabilidad ruminal de la MS de S. setosum.
\end{abstract}

Palabras claves: bovino, rumen, degradabilidad, cinética, Sorghastrum setosum.

\begin{abstract}
Slanac, A.L.; Kucseva, C.D.; Balbuena, O.; Rochinotti, D.: Bovine ruminal degradation of Sorghastrum setosum dry matter from different cutting time during autumn. Rev. vet. 22: 2, 105-108, 2011. To evaluate ruminal dry matter (DM) degradation of Sorghastrum setosum in bovine during autumn, samples from 15, 30 and 45 day regrow were cut. Ruminalcannulated, $550 \mathrm{~kg}$ average liveweight steers were used to incubate in situ dacron bags at the following incubation times: $0,3,6,12,24,48,72$ and $120 \mathrm{~h}$. Bags were taken out of the rumen at the same time and dried at $60^{\circ} \mathrm{C}$ for $72 \mathrm{~h}$ and weighted. Weight loss was assumed as disappearance of DM from the rumen. Data were analyzed by the GLM procedure of the SAS package. Soluble fraction, degradation rate of fraction, ruminal effective degradation of DM at 2 and $4 \%$ passage rate, were not affected $(p>0.05)$ by regrow time. A trend $(p=0.09)$ was observed for lag time among regrow time. It was concluded that during autumn, cutting time did not affect ruminal DM degradation of Sorghastrum setosum.
\end{abstract}

Key words: cattle, rumen, degradability, kinetic, Sorghastrum setusum.

\section{INTRODUCCIÓN}

La base del recurso forrajero del nordeste argentino es el pastizal natural, con predominio de especies de crecimiento primavero-estivo-otoñal, lo cual determina que durante el periodo invernal, con bajas temperaturas y heladas, ocurra un estancamiento en la producción de forraje y por lo tanto un bache forrajero, que

Recibido: 20 agosto 2011 / Aceptado: 16 septiembre 2011 afecta particularmente aquellas categorías de mayores requerimientos.

Una gran ventaja de los rumiantes es su capacidad de aprovechar como nutrientes los productos de la digestión microbiana de la pared celular vegetal. Desde este punto de vista, el aprovechamiento de recursos lignocelulósicos de baja calidad, por su relativa abundancia y bajo costo, tiene especial trascendencia en sistemas extensivos y semi-extensivos de producción, especialmente en regiones con escasa disponibilidad 
de otras fuentes de alimentos para el ganado. El conocimiento de los mecanismos implicados en la acción de la población ruminal sobre los forrajes es fundamental para la optimización de su utilización ${ }^{7}$.

Los campos bajos y anegadizos, cubiertos de pajas ("pajonal”), poseen otras especies vegetales más apetecibles para el rumiante, que permanecen cubiertas por aquéllas. Es el caso de algunas especies de Paspalum (pasto macho, pasto miel, pasto horqueta), que si bien están disponibles para el animal, éste las utiliza en forma inversamente proporcional a la densidad del pajonal. En todo el chaco húmedo, son característicos los pajonales de paja amarilla, paja boba, paja de techar y otras ${ }^{11}$. En cada sitio puede haber diferentes comunidades (combinaciones de especies), que dependen del manejo a que fue sometido el campo. Hay combinaciones más productivas que otras, debido a que el potencial de producción de las especies que las componen es mayor o bien a que poseen mayor cantidad de especies forrajeras y menos malezas ${ }^{3}$.

La carga afecta la producción de forraje por lo menos de dos formas diferentes, por el efecto del pastoreo sobre el vigor de las especies y por el cambio de especies que produce. El pastizal natural se puede manejar con una carga promedio estipulada para un lapso de por ejemplo 10 años; el problema de este tipo de manejo es que en años buenos sobra pasto, pero falta en los malos. En ambos casos disminuye la ganancia de kg de carne/ ha y posiblemente se perjudica al pastizal ${ }^{3}$.

La concentración proteica de los pastos alcanza valores máximos en otoño y mínimo en invierno y verano, con valores intermedios en primavera ${ }^{9}$. Si bien los pastizales de la región tienen pocas especies invernales, el crecimiento en este período no es nulo, la tasa diaria de crecimiento durante estos meses (junio, julio y agosto) es de 6-7 kg MS/ha/día ${ }^{15}$. El patrón de crecimiento de los distintos tipos de pastizales es muy similar y con una marcada estacionalidad, que a los fines prácticos de su manejo es importante conocer, ya que la capacidad de carga de acuerdo a la producción de pasto varía mucho a través del año, cualquiera sea el tipo de pastura.

También es importante tener en cuenta la cantidad de materia seca (MS) producida durante el año por cada tipo de pastura, producción que está determinada por las especies botánicas en relación a las condiciones de suelo y manejo que soportan ${ }^{15}$. Es bien conocido que el proceso de digestión de los carbohidratos estructurales que forman la pared celular de los forrajes es precedido por una fase de retardo, llamada también de incubación, de latencia o pre-fermentativa ${ }^{14}$, necesaria para la adhesión de bacterias celulolíticas al substrato insoluble ${ }^{19}$

Analizar los alimentos base es entonces importante para caracterizar nutricionalmente los mismos y para seleccionar mejor los suplementos a utilizar, de tal manera que se optimice la producción. El mejor indicador de la calidad de un alimento dado es la performance animal, y los tres parámetros que la constituyen son el consumo, la digestibilidad y la eficiencia de utilización. Siendo que las variaciones en el consumo explican entre un 60 y $90 \%$ de la variación en la energía digestible, sería conveniente entonces determinar aquellas características de los forrajes más asociadas al consumo y a la digestibilidad ${ }^{4}$.

El objetivo del presente trabajo fue evaluar en época otoñal la cinética de la degradación ruminal de la materia seca de Sorghastrum setosum (paja Amarilla) en rumen de bovinos alimentados con pastura natural.

\section{MATERIAL Y MÉTODOS}

El material vegetal evaluado fue recolectado en la Estación Experimental Colonia Benítez del INTA (Chaco, Argentina). Previo corte de limpieza con guadañadora mecánica y retirado del material cortado, las muestras de S. setosum fueron tomadas por medio de cortes con tijeras a $10 \mathrm{~cm}$ de altura de todo el material disponible en condición de pastoreo, dentro de un marco de 50 x $50 \mathrm{~cm}$, con cortes a los 15, 30 y 45 días de rebrote.

Una vez pesadas, las muestras se colocaron en bolsas de papel y fueron puestas a secar en estufa de aire forzado a $60^{\circ} \mathrm{C}$ durante $72 \mathrm{~h}$, posteriormente fueron pesadas y luego molidas con molino de cuchillas con mallas de $2 \mathrm{~mm}$, colocándolas en cajas para su posterior análisis. Para medir la desaparición de MS se utilizaron dos novillos cruza cebú de $550 \mathrm{~kg}$ de peso vivo provistos de fístula ruminal, que fueron mantenidos en potreros con pastura natural. Los animales recibieron ad libitum un suplemento mineral que contenía $12 \% \mathrm{Ca}$, $8 \%$ P y microelementos vehiculizados en sal común.

Se utilizó la técnica de suspensión in situ de bolsas de dacrón ${ }^{13}$. En cada bolsa, de 9,5 x $18 \mathrm{~cm}$, con una porosidad de $50 \mathrm{um}$, se colocaron $5 \mathrm{~g}$ de material seco de la pastura, que fueron introducidos en el rumen en forma secuencial con los siguientes tiempos: 120; 72; $48 ; 24 ; 12 ; 6 ; 3$ y 0 horas. Luego del tiempo de incubación correspondiente, las bolsas fueron retiradas del rumen y sumergidas en agua fría por $5 \mathrm{~min}$, después lavadas bajo agua corriente hasta que ésta escurriera aparentemente limpia y por último secadas en horno a $60^{\circ} \mathrm{C}$ durante $72 \mathrm{~h}$ y pesadas.

La pérdida de peso se consideró como el valor de desaparición de la MS. Los datos obtenidos en degradación de la materia seca (MS \%) fueron ajustados a un modelo convencional ${ }^{12}$ : MS $\%=\mathrm{a}+\mathrm{b}\left(1-\exp ^{-\mathrm{ct}}\right)$, donde MS \%: degradabilidad de la MS al tiempo " $t$ " \%; "a" es la fracción soluble; "b" la fracción lentamente degradable; "c" la tasa de degradación de b, horas; " $t$ " tiempo de incubación en rumen, horas; "exp" base de los logaritmos naturales. Se calculó además la degradabilidad efectiva de acuerdo a la ecuación de los mismos autores: $\mathrm{DE} \%=\mathrm{a}+\left[\left(\mathrm{b}^{*} \mathrm{c}\right) /(\mathrm{c}+\mathrm{kp})\right]$ donde $\mathrm{DE}$ es la degradabilidad efectiva (DE \%) a, b y c son los mismos de la ecuación anterior y $\mathrm{kp}$, es la tasa de pasaje (2 y $4 \% /$ hora $)^{12}$. Se analizó el efecto de la edad de rebrote sobre la degradabilidad, mediante análisis de varianza 
a través de procedimiento de modelos lineales generales GLM del paquete estadístico SAS (2008) ${ }^{17}$. Para la comparación de medias se efectuó prueba de Tukey. Se aceptó la existencia de significación estadística cuando $\mathrm{p}<0,05$.

\section{RESULTADOS Y DISCUSIÓN}

La degradación de MS no registró diferencias para las distintas edades de corte ni tampoco para los distintos horarios de incubación. Asumiendo para S. setosum una tasa de pasaje del $2 \%$, pudo apreciarse que la degradabilidad efectiva reveló una tendencia más veloz para las muestras de menor edad $(46,03 ; 46,61$ y $44,98 \%$ para las edades de 15,30 y 45 días respectivamente).

En la Tabla 1 se resumen los resultados obtenidos para la degradabilidad ruminal de MS para el rebrote de 15,30 y 45 días, donde el análisis estadístico mostró que no se detectaron diferencias significativas ( $p>$ $0,05)$, para la fracción soluble (a), fracción de degradación lenta (b), la fracción indigestible (c), tasa de degradación (kd) y degradación ruminal al 2 y 4\%. El análisis de la varianza solo detectó una tendencia a ser diferente entre edades de rebrote para el tiempo de inicio de la degradación (lag hs), $\mathrm{p}=0,0876$. El período pre-fermentativo ${ }^{14,19}$ para $S$. setosum fue de 7,$57 ; 7,06$ y $6,73 \mathrm{~h}$ para rebrotes de $15 ; 30$ y 45 días, respectivamente.

Para los constituyentes de la pared celular de $S$. setosum, se encontraron valores de degradabilidad potencial de la MS $(\mathrm{a}+\mathrm{b})$ que oscilaron entre $55,68 \%$ a los 15 días y $52,62 \%$ a los 45 días. Existen diferencias entre especies forrajeras en cuanto a morfología y tipo de bacterias asociadas con el proceso de degradabilidad ruminal de la pared celular ${ }^{1}$.

La degradabilidad de S. setosum resultó inferior a la encontrada en investigaciones anteriores para esta misma pastura ${ }^{18}$. El pastizal muestra mayores niveles de digestibilidad de MS en primavera; a medida que avanza el verano y el otoño las plantas maduran, aumentando el contenido de pared celular y disminuyendo el de proteína ${ }^{16}$.

El análisis de la variancia no mostró efectos significativos $(p>0,05)$ para los distintos horarios de incubación, en las diferentes edades de rebrote (Figura 1). Los valores hallados en el presente ensayo concuerdan con reportes mencionados por otros autores que relatan la disminución de la desaparición de MS a medida que se incrementa la edad de la planta, respuesta debida a la lignificación de la fibra, la cual se acentúa con la madurez del pastizal y se ve favorecida por déficit hídrico ${ }^{10}$. La calidad nutricional no cambia drásticamente con la madurez de la planta. La degradabilidad ruminal de la MS fluctuó dentro de niveles aceptables, si los comparamos con datos registrados en otras especies ${ }^{8}$.

Teniendo en cuenta los valores de desaparición de MS para los horarios de la época otoñal, surge que $S$. setosum tuvo mayor degradabilidad a la tasa del $2 \%$
Tabla 1. Parámetros de degradabilidad ruminal in situ de MS de S. setosum a diferentes edades de rebrote.

\begin{tabular}{lccccc}
\hline \multirow{2}{*}{ parámetro } & \multicolumn{3}{c}{ edad de rebrote (días) } & \multirow{2}{*}{ EE } & p \\
\cline { 2 - 4 } & 15 & 30 & 45 & & \\
\hline a (\%) & 33,24 & 33,09 & 31,39 & 0,62 & 0,270 \\
b (\%) & 22,44 & 20,29 & 21,23 & 3,20 & 0,899 \\
c (\%) & 44,31 & 46,61 & 47,37 & 2,73 & 0,747 \\
kd (\%) & 0,029 & 0,040 & 0,054 & 0,017 & 0,638 \\
lag (horas) & 7,57 & 7,06 & 6,73 & 0,13 & 0,088 \\
DR 2\% & 46,03 & 46,61 & 44,98 & 2,39 & 0,893 \\
DR 4\% & 42,30 & 43,24 & 41,69 & 2,22 & 0,890 \\
\hline
\end{tabular}

EE: error estándar; p: probabilidad; a: fracción soluble; b: fracción de degradación lenta; c: tasa de degradación de b; kd: tasa de degradación; lag: tiempo de inicio de la degradación; DR: degradación ruminal.

que a la del 4\%, para todas las edades. Existen estudios sobre otras especies de menor importancia en el pastizal, que presentan buena degradabilidad en distintos momentos, sobre todo cuando las especies invernales reducen su crecimiento durante el verano ${ }^{5}$.

En general, las diferencias en degradabilidad efectiva entre cultivares de verdeos en otoño se correspondieron a diferencias en la relación entre la fracción soluble y la fracción insoluble potencialmente degradable y a diferencias en la tasa fraccional de degradación. La fracción indegradable resultó similar $(p>0,05)$, coincidiendo con lo reportado para el comportamiento entre diferentes cultivares ${ }^{6}$. Se obtuvieron valores para parámetros de degradabilidad ruminal de la MS de $\mathrm{Bra}$ chiaria humidicola en diferentes épocas y sistemas, detectándose diferencias significativas entre épocas para degradabilidad inicial, degradación potencial, tasa de degradación y fracción degradada por los microorganismos, las cuales fueron superiores en la época lluviosa $^{2}$.

Surge como conclusión que la edad de corte no influyó sobre la degradabilidad ruminal de la materia seca de $S$. setosum en época otoñal, lo cual sugiere que tampoco varió su calidad nutricional.

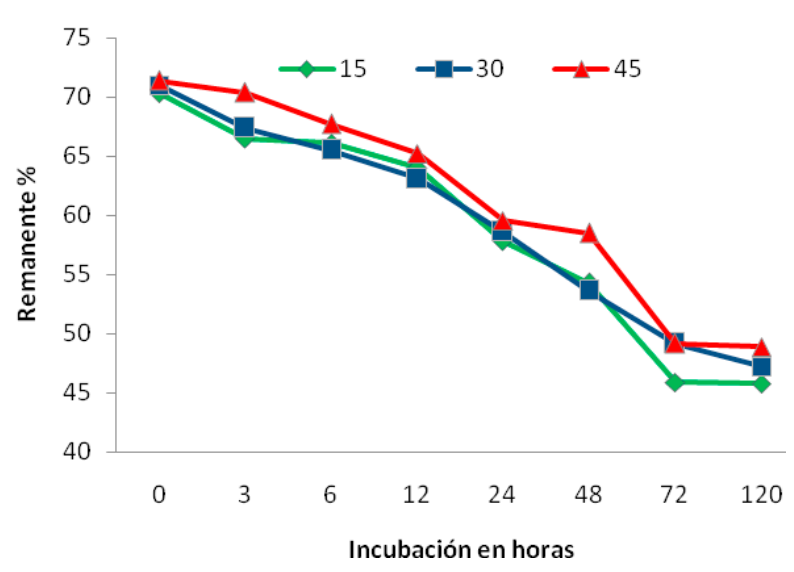

Figura 1. Curvas de degradación de S. setosum de 15, 30 y 45 días de rebrote en período otoñal. 


\section{REFERENCIAS}

1. Akin DE. 1979. Histological and physical factors affecting digestibility of forages. Agron J 81: 17-25.

2. Barajas CR, Obregón JF, Romero J. 1992. Digestibilidad in situ de ocho pastos en dos cortes desarrollados en temporal en el sur de Sinaola. Anales IV Reunión de Nutrición Animal, Monterrey, México, p.115-119.

3. Bissio JC. 1994. La carga animal. Información para extensión No 53 del INTA Reconquista (Santa Fe, Argentina), 9 p.

4. Cherney DJ. 2000. Forage evolution in ruminant nutrition, CABI, Wallingford, UK, p. 281-300.

5. Estelrich HD, Cano AE. 2006. Dinámica de la degradabilidad ruminal in sacco de la fitomasa aérea de especies nativas de la región semiárida pampeana (Argentina). On line: www.agro.unlapam.edu.ar.

6. Ferri CM, Stritzler NP. 2006. Comportamiento de verdeos invernales en Santa Rosa, La Pampa. II. Estimación de la degradabilidad ruminal in sacco. On line: www.agro. unlapam.edu.ar.

7. Fondevila M. 1998. Procesos implicados en la digestión microbiana de los forrajes de baja calidad. Rev Fac Agron Zaragoza, España, 15: 87-106.

8. Franco MH, Ibrahim M, Pezo D, Camero A, Araya J. 1997. Efecto del premarchitamiento y la adición de melaza sobre la calidad nutricional y el consumo de Cratylia argentea en bovinos bajo pastoreo de Hyparrhemnia rufa durante la época seca en el trópico subhúmedo de Costa Rica. Tesis de Maestría, Univ. Turrialba (Costa Rica), 36 p.

9. Iacopini ML, Pueyo JM, Grancelli RJ, Vicenti JA. 2001. Calidad del forraje del campo natural en la provincia de Entre Ríos. On line: www.mejorpasto.com.
10. Lascano C. 1979. Determinants of grazed forage voluntary intake in cattle. Tesis Ph.D. Texas A y M University, USA, $215 \mathrm{p}$.

11. Luisoni LH. 1995. Características del pastizal de zonas subtropicales que afectan el consumo y la producción animal. Boletín INTA Reconquista (Argentina), 11 p.

12. Orskov ER, McDonald IM. 1979. Estimation of protein degradability in the rumen from incubation measurement weighted according to rate of passage. J Agric Sci 96: 499503.

13. Orskov ER, Hovell FD, Moul F. 1980. Uso de la técnica de la bolsa de nylon para evaluación de los alimentos. Prod Anim Trop 5: 195-213.

14. Pezo D. 1990. Medición de las tasas de degradación ruminal en alimentos. En: Nutrición de rumiantes, guía metodológica de investigación (Ruiz M, Ruiz A, ed.), Publ. IICA, San José (Costa Rica), p. 115-126.

15. Pizzio R. 2003. Herramientas para el manejo del campo natural. Noticias \& Comentarios (INTA Mercedes, Corrientes, Argentina) 373: 1-4.

16. Sampedro D, Vogel O, Celser R. 2004. Suplementación de vacunos en pastizales naturales. Serie Técnica $N^{o} 34$, INTA Mercedes (Corrientes, Argentina), $16 \mathrm{p}$.

17. SAS Institute Inc. 2008. SAS/TAT ${ }^{T M}$, guide for personal computers, version 9.2. Ed. SAS Institute, Cary, NC.

18. Slanac AL, Balbuena O, Rochinotti D, Navamuel JM, Dayer DO. 2006. Degradación ruminal de la materia seca de dos especies del pastizal natural del nordeste argentino. On line: www.unne.edu.ar.

19. Tamminga S. 1982. Energy protein relationships in ruminant feeding. In: Protein contribution of feedstuffs for ruminants: application to feed formulation (Miller EL, Pike IH, Van Es AJ, ed.), Butterworths, London, p. 4-15. 